\title{
Visual stimulus-seeking behavior in three homogeneous strains of mice
}

\author{
MERLE E. MEYER \\ University of Florida, Gainesville, Florida 32611 \\ and \\ LAWRENCE H. FRANK \\ Western Washington University, Bellingham, Washington 98225
}

\begin{abstract}
Activity and exploratory behaviors in three strains of mice (CBA/J, BALB/cJ, DBA/2J) were investigated on 2 consecutive days using a Greek cross maze with black, white, checkered, and striped compartments. Two measures were taken: frequency of entrance into each compartment and consecutive 10-sec sampling of the animals' location throughout each 3 -min trial. The results indicated differences among strains of both measures. These results were compared with prior findings with Swiss mice, rats, and gerbils.
\end{abstract}

Thompson and Lippman (1972) investigated exploration and activity in rats and gerbils using a Greek cross maze with black, white, striped, and checkered compartments. These investigators reported that gerbils were more active than rats (higher frequency of entering compartments) and that gerbils were more varied in their preferred compartments than were rats, who preferred the black arm of the maze. The present experiment was designed to expand the generality of the Thompson and Lippman findings by investigating activity and exploratory behavior in three homogeneous strains of mice.

\section{METHOD}

The subjects were 24 male mice $(8-\mathrm{CBA} / \mathrm{J}, 8-\mathrm{BALB} / \mathrm{cJ}$, and $8-\mathrm{DBA} / 2 \mathrm{~J}$ ) that were obtained from a commercial supplier. The mice were approximately 210 days of age at the time of testing, and they were individually housed, with food and water available ad lib.

The apparatus was a Greek cross maze constructed from plywood, with arms $33 \mathrm{~cm}$ long, $25 \mathrm{~cm}$ wide, and $48 \mathrm{~cm}$ high (Thompson \& Lippman, 1972). The floor was painted flat gray, with a line drawn at the entrance of each arm. One arm was painted flat black, and the opposite arm was painted flat white. Another arm was painted with $45-$ deg angle alternating $2.5-\mathrm{cm}$ black and white stripes; its opposite arm was painted with $2.5-\mathrm{cm}$-square black and white checks. The reflected illumination from the walls of each arm was: black, $2 \mathrm{fc}$; white, $16 \mathrm{fc}$; stripes, $7 \mathrm{fc}$; and checks, $7 \mathrm{fc}$ (as measured with a Model 614 Weston light meter).

Each subject was given a 3-min trial on each of 2 consecutive days. The animal was placed in the center compartment of the maze in the same general direction as the maze was systematically rotated, so that the animals were facing each arm of the maze equally often.

An observer recorded two measures: the frequency with which each animal entered each arm or compartment (an entrance

Reprint requests should be sent to Merle E. Meyer, Department of Psychology, University of Florida, Gainesville, Florida 32611. response was recorded when the head and front paws were across the entrance line of a compartment) and a behavior sampling of which compartment the animal was in at the end of each $10 \mathrm{sec}$ of the 3-min, or $180-\mathrm{sec}$, trial. The center compartment was counted in this time sample as a compartment. While these two measures are not mutually exclusive, the frequency of compartment entrances may be considered an index of activity, and the time sampling may be considered a preference measure.

\section{RESULTS AND DISCUSSION}

The experimental design for the frequency of entrance into each compartment of the maze was a 3 by 2 by 4 factorial composed of three strains (CBA/J, BALB/cJ, DBA/2J), 2 days of testing, and four compartments (black, white, striped, checkered). The analyses of this measure revealed a significant strain effect $[F(2,21)=6.69, p<.05]$ and a significant compartment effect $[F(3,63)=11.57, p<.01]$. All other analyses were not statistically significant. The nonsignificant Compartment by Species interaction is presented in Figure 1. Subsequent (Newman-Keuls) analyses of the strain effect indicated that the BALB/cJ strain had a significantly higher mean frequency of entrance that the other two strains and that the CBA/J strain differed significantly from the DBA $/ 2 J$ strain $(p<.05)$. The subsequent analysis of the compartment effects revealed a significant preference for the black compartment over both the striped and checkered compartments, which were preferred to the white one $(p<.05)$.

In general, the frequency-of-entrance data for these three homogeneous strains of mice are similar to those for the Sprague-Dawley rats, which show the same order of compartment preference (Thompson \& Lippman, 1972). However, it is not clear from the data if the frequency of entrance is a function of visual complexity or of intensity of illumination. On the other hand, 
the present data are at variance with the entrance data for the heterogeneous Swiss Webster strain of mice, which showed a significant frequency of entrance into the checkered compartment of the maze on the 1st day and a shift to the white compartment on the 2nd day of testing (Meyer \& McCormick, 1979). In the present study, the differences between days were approximately equal.

The analyses of the time-sample data indicated a significant compartment effect $[F(4,84)=22.66, p<.01]$ and a significant Compartment by Strain interaction $[F(4,84)=4.16, p<.05]$. All other comparisons were not significant. The Compartment by Strain interaction is shown in Figure 2. Subsequent analyses of this interaction indicated that the DBA/ $2 J$ strain of mice preferred the black compartment over the equally preferred white, checkered, and striped compartments and preferred these over the center compartment $(p<.05)$. Similarly, the CBA/J strain exhibited a preference for the black compartment over all others $(p<.05)$. On the other hand, the $\mathrm{BALB} / \mathrm{cJ}$ strain showed a slight preference for the striped compartment over the white and center compartments $(p<.05)$ and preferred the other compartments equally.

The time-sample data for the $\mathrm{DBA} / 2 \mathrm{~J}$ and $\mathrm{CBA} / \mathrm{J}$ strains of mice are, likewise, consistent with the

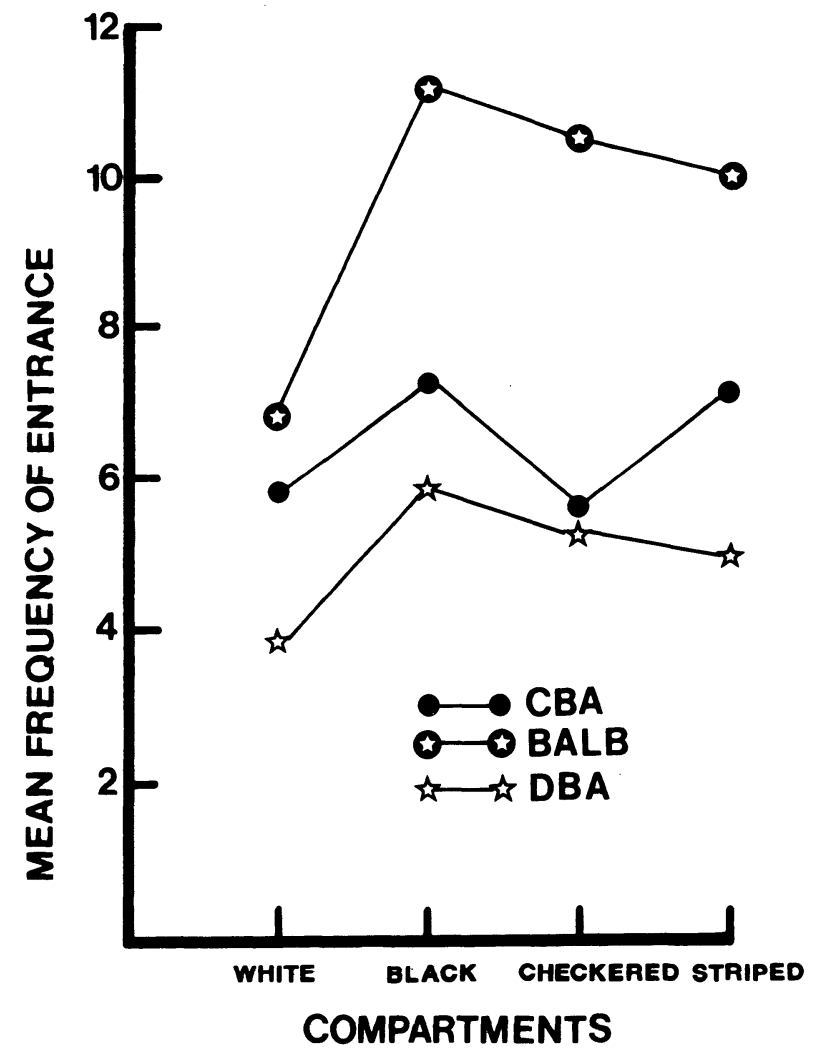

Figure 1.

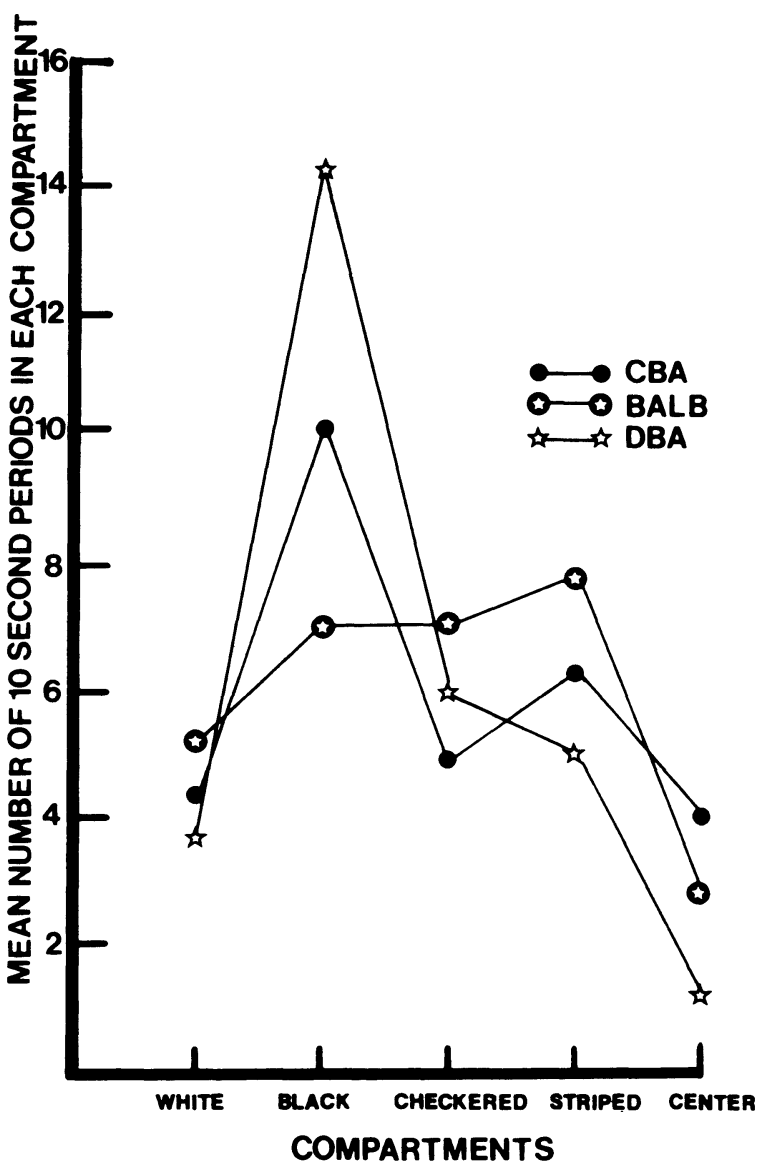

Figure 2.

Thompson and Lippman (1972) study with rats, in which these strains preferred the black compartment and avoided the more visually complex or bright compartments. The $B A L B / c J$ strain, on the other hand, explored more (frequency of entrance), and their preference differed from the other strains of mice but were somewhat similar to the findings with gerbils (Thompson \& Lippman, 1972). Gerbils exhibited a preference for the checkered compartment over the striped one and preferred the other compartments equally, whereas in the present study the BALB/cJ mice preferred the striped compartment over the white and center compartments and preferred the other compartments equally.

\section{REFERENCES}

Meyer, M. E., \& McCormick, C. E. Infantile handling and adult visual stimulus seeking behavior in mice. Psychological Reports, 1979, 44, 441-414.

Thompson, R. W., \& Lippman, L. G. Exploration and activity in the gerbil and rat. Journal of Comparative and Physiological Psychology, 1972, 80, 439-448.

(Received for publication April 1, 1980.) 